\title{
Adaptasi Revised-Multidimesional Scale of Perceived Social Support pada Guru di Kota Bandung
}

\author{
Tri Dini Oktarina*, Surya Cahyadi, Hery Susanto \\ Program Studi Profesi Psikologi, Fakultas Psikologi, Universitas Padjadjaran \\ *Corresponding Author. Email: tridini.oktarina@gmail.com
}

\begin{abstract}
This study aims to test the reliability and validity of the Revised Multidimensional Scale of Perceived Social Support (R-MSPSS) which has been translated to bahasa Indonesia. This study uses a quantitative approach. Data was obtained from 285 teachers in Bandung (include elementary school, junior high school, and high school) who implemented distance learning during the Covid-19 pandemic. The sampling technique used was convenience sampling. The data were collected using a questionnaire in the form of google form that was distributed through social media. The data analysis techniques in this study was an internal consistency test using Cronbach's alpha to calculate the reliability of the instrument and confirmatory factor analysis with diagonally weighted least square estimation to prove construct validity using the JASP version 0.14 program. The results of this study indicate that the R-MSPSS has good reliability with the Cronbach's alpha value on the total score and the score for each dimension of more than 0,7 . The result of factor confirmatory analysis shows that the R-MSPSS model with 4 factors is in accordance with the measured construct. The results of this study indicate that the R-MSPSS is a reliable and valid instrument for measuring teachers' perceived social support.
\end{abstract}

\begin{abstract}
Abstrak: Tujuan dari penelitian ini adalah menguji reliabilitas dan validitas Revised Multidimensional Scale of Perceived Social Support (R-MSPSS) yang telah diterjemahkan ke bahasa Indonesia. Penelitian ini menggunakan pendekatan kuantitatif. Responden yang terlibat dalam penelitian ini adalah 285 guru SD, SMP, dan SMA/SMK di Kota Bandung yang melaksanakan pembelajaran jarak jauh selama masa pandemi Covid-19. Teknik sampling yang digunakan adalah convenience sampling. Data diperoleh menggunakan kuesioner berbentuk isian google form yang disebarkan melalui media sosial. Teknik analisis data pada penelitian ini berupa uji konsistensi internal menggunakan cronbach's alpha untuk menghitung reliabilitas instrumen dan analisis faktor konfirmatori dengan estimasi diagonally weighted least square untuk membuktikan validitas konstruk yang dilakukan menggunakan program JASP versi 0.14. Hasil penelitian ini menunjukkan bahwa R-MSPSS memiliki reliabilitas yang baik dengan nilai cronbach's alpha pada skor total maupun pada skor tiap dimensi lebih dari 0,7. Hasil analisis konfirmatori faktor menunjukkan bahwa model R-MSPSS dengan 4 faktor sesuai dengan konstruk yang diukur. Hasil penelitian ini menunjukkan bahwa R-MSPSS merupakan instrumen yang reliabel dan valid untuk mengukur persepsi dukungan sosial guru.
\end{abstract}

\section{Article History}

Received: $17-12-2020$

Revised: 01-02-2021

Accepted: 20-04-2021

Published: 07-06-2021

\section{Key Words:}

R-MSPSS, Perceived

Social Support,

Teacher, Confirmatory

Factor Analysis.

\section{Sejarah Artikel}

Diterima: 17-12-2020

Direvisi: 01-02-2021

Disetujui: 20-04-2021

Diterbitkan: 07-06-2021

\author{
Kata Kunci: \\ R-MSPSS, Perceived \\ Social Support, Guru, \\ Analisis Faktor \\ Konfrmatori.
}

How to Cite: Oktarina, T., Cahyadi, S., \& Susanto, H. (2021). Adaptasi Revised-Multidimesional Scale of Perceived Social Support pada Guru di Kota Bandung. Jurnal Kependidikan: Jurnal Hasil Penelitian dan Kajian Kepustakaan di Bidang Pendidikan, Pengajaran dan Pembelajaran, 7(2), 289-296. doi:https://doi.org/10.33394/jk.v7i2.3259

https://doi.org/10.33394/jk.v7i2.3259

This is an open-access article under the CC-BY-SA License.

\section{Pendahuluan}

Pekerjaan sebagai guru dianggap sebagai pekerjaan yang rentan terhadap stres. Beban kerja yang banyak serta perilaku murid yang beragam menjadi beberapa sumber stres bagi 
guru (Clipa, 2017). Social support, yaitu penyediaan sumber psikologis dan material dari jaringan sosial yang ditujukan untuk bermanfaat bagi kemampuan individu dalam mengatasi stres (Cohen, 2004) diyakini memiliki fungsi sebagai penghambat stres (Thoits, 2011). Social support dapat mengarahkan guru untuk menggunakan coping yang lebih efektif dan juga melakukan penilaian ulang terhadap situasi yang dianggap membebani guru. Selain sebagai penghambat stres, social support juga diyakini memiliki dampak positif secara langsung terhadap kesehatan mental individu (Thoits, 2011). Berdasarkan fungsi tersebut, dukungan dari orang-orang terdekat yang diterima guru meski tidak sedang merasa tertekan dapat berdampak langsung pada kebahagiaan guru.

Social support dapat diukur dengan dua cara yaitu mengukur received social support untuk melihat dukungan yang diterima oleh individu dan mengukur perceived social support untuk melihat penilaian individu mengenai dukungan yang diterima (Lakey \& Cohen, 2000). Perceived support sebagai persepsi seseorang terhadap ketersediaan sumber dukungan dapat memengaruhi penilaian seseorang terhadap suatu peristiwa yang mungkin mengakibatkan stres (LAM, 2019). Kehadiran keluarga, teman, maupun rekan kerja dapat memengaruhi pemaknaan guru terhadap situasi yang mungkin dianggap sebagai tekanan dan membuat guru merasa lebih berdaya dalam menghadapi tantangan. Kehadiran orang-orang terdekat tersebut dapat membuat guru merasa memiliki orang-orang yang siap membantunya sehingga memengaruhi emosi yang dirasakan serta cara menghadapi situasi tersebut (LAM, 2019). Di antara perceived dan received social support, pengukuran perceived social support memiliki lebih banyak hubungan dengan keadaan psikologis seseorang (LAM, 2019).

Multidimesional Scale of Perceived Social Support (MSPSS) merupakan instrumen yang pertama kali dikembangkan oleh Zimet, Dahlem, Zimet, dan Farley untuk mengukur persepsi tentang dukungan sosial (Zimet, Dahlem, Zimet, \& Farley, 1988). Instrumen ini merupakan instrumen yang singkat karena hanya memiliki 12 item sehingga ideal digunakan bersama beberapa kuesioner untuk suatu penelitian. MSPSS mengukur persepsi tentang dukungan sosial dari tiga sumber yaitu teman, keluarga, dan significant other. MSPSS memiliki reliabilitas dan validitas yang baik di sampel mahasiswa. Reliabilitas pada MSPSS dengan melihat reliabilitas internal dilihat dari koefisien Cronbach's alpha sebesar 0,91, 0,87, dan 0,85 pada subskala significant other, keluarga, dan teman. Berdasarkan test-retest reliability, didapatkan hasil sebesar $0,72,0,85$, dan 0,75 pada subskala significant other, keluarga, dan teman. Secara keseluruhan, MSPSS memiliki reliabilitas sebesar 0,85. Validitas untuk MSPSS diuji melalui validitas konstruk. MSPSS dibandingkan dengan instrumen depresi dan kecemasan. Dari perbandingan tersebut ditemukan bahwa MSPSS memiliki hubungan yang negatif dengan depresi dan kecemasan (Zimet et al., 1988).

MSPSS sudah diadaptasi ke beberapa bahasa seperti Prancis, Yunani, Korea, Cina, Malaysia, dan bahasa-bahasa lainnya pada populasi yang beragam dan memiliki reliabilitas dan validitas yang baik (Denis, Callahan, \& Bouvard, 2015; Guan, Seng, Hway Ann, \& Hui, 2015; Lee, Moy, \& Hairi, 2017; Park, Nguyen, \& Park, 2012; Theofilou, 2015). MSPSS juga telah digunakan untuk mengukur perceived social support guru pada penelitian di Malaysia (Lee et al., 2017). Salah satu penelitian di China melakukan modifikasi terhadap item MSPSS untuk lebih menyesuaikan dengan bahasa dan konten guru (Ho \& Chan, 2017). Dari tiga sumber social support yang disusun dalam MSPSS yaitu teman, keluarga, dan significant other, Ho \& Chan (Ho \& Chan, 2017) mengganti sumber significant other menjadi sumber dari kepala sekolah dan kolega guru. Adaptasi yang diberi nama Revised-Multidimensional Scale of Perceived Social Support (R-MSPSS) diujikan kepada guru-guru di Hongkong, China (Ho \& Chan, 2017). Penambahan sumber dukungan pada populasi guru telah diprediksi oleh Zimet, Dahlem, Zimet, dan Farley (Zimet et al., 1988) karena MSPSS pada 
awalnya diuji pada mahasiswa. Zimet, Dahlem, Zimet, dan Farley (Zimet et al., 1988) beranggapan bahwa pada populasi atau peran yang berbeda ada kemungkinan sumber dukungan akan berbeda pula.

Reliabilitas R-MSPSS pada keempat sumber social support yang dilihat melalui internal consistency berada pada rentang 0,84 hingga 0,9 (Ho \& Chan, 2017). Sementara itu, validitas yang diuji dengan confirmatory factor analysis (CFA) memiliki kriteria good fit setelah dilakukan modifikasi post hoc berdasarkan modification indices. Berdasarkan convergent validity, R-MSPSS memiliki korelasi positif dengan self-esteem. Selain itu, berdasarkan discriminant validity ditemukan bahwa sumber social support yaitu teman, keluarga, dan kepala sekolah menunjukkan perbedaan dengan dimensi burnout (Ho \& Chan, 2017).

MSPSS sudah digunakan di Indonesia pada populasi yang beragam misalnya pada penelitian mengenai penyintas bencana (Laksmita, Chung, Liao, \& Chang, 2020), pasien hipertensi (Giena, Thongpat, \& Nitirat, 2018), dan guru (Akbar \& Tahoma, 2018). Dari penelitian-penelitian yang mengukur perceived social support pada guru di Indonesia, belum ada yang menggunakan versi R-MSPSS yaitu MSPSS yang sudah disesuaikan dengan konteks guru. Dengan demikian, penelitian ini bertujuan untuk menguji reliabilitas dan validitas R-MSPSS yang telah diterjemahkan ke bahasa Indonesia. Manfaat dari penelitian ini adalah menyediakan instrumen perceived social support untuk konteks guru dalam bahasa Indonesia yang sudah teruji reliabilitas dan validitasnya sehingga dapat digunakan untuk penelitian yang ingin mengukur perceived social support pada guru, terutama di Indonesia.

\section{Metode Penelitian}

Penelitian ini menggunakan pendekatan kuantitatif. Teknik sampling yang digunakan adalah convenience sampling. Responden pada penelitian ini adalah 285 guru SD, SMP, dan SMA/SMK Kota Bandung yang melaksanakan pembelajaran jarak jauh selama pandemi Covid-19. Instrumen penelitian yang digunakan pada penelitian ini adalah Revised Multidimensional Scale of Perceived Social Support (R-MSPSS). Instrumen ini berisi 16 pernyataan yang terbagi menjadi 4 subskala (masing-masing berisi 4 pernyataan) yaitu sumber dukungan dari teman, sumber dukungan dari keluarga, sumber dukungan dari rekan guru, dan sumber dukungan dari kepala sekolah. Terdapat 7 pilihan jawaban dari 1 (sangat tidak setuju) hingga 7 (sangat setuju). Semakin tinggi skor pada setiap subskala menunjukkan kepuasan yang lebih tinggi terhadap dukungan sosial yang dirasakan dari setiap sumber (Ho \& Chan, 2017). Data diperoleh dengan menyebarkan kuesioner yang berbentuk isian google form yang disebarkan kepada responden berupa tautan melalui media sosial seperti whatsapp, facebook, Instagram, dan twitter. Penjelasan mengenai pelaksanaan penelitian dan informed consent dapat diakses responden melalui tautan yang telah disebarkan. Pengambilan data dilakukan pada bulan September hingga bulan November 2020. Penelitian ini telah mendapatkan persetujuan dari Komisi Etik Penelitian Universitas Padjadjaran dengan nomor: 758/UN6.KEP/EC/2020 dan izin penelitian dari Dinas Pendidikan Jawa Barat (untuk jenjang SMA/SMK) dan Dinas Pendidikan Kota Bandung (untuk jenjang SD dan SMP).

Setiap item R-MSPSS diterjemahkan ke Bahasa Indonesia oleh sarjana psikologi yang merupakan penutur asli bahasa Indonesia dan menguasai bahasa Inggris. Item R-MSPSS yang sudah berbahasa Indonesia diterjemahkan menjadi bahasa Inggris oleh sarjana psikologi yang menguasai bahasa Indonesia dan bahasa Inggris. Hasil terjemahan ditelaah oleh seorang doktor psikologi untuk memastikan kesesuaian item hasil terjemahan dengan item asli. Analisis data pada penelitian dilakukan dengan program JASP versi 0.14 (JASP Team, 2020). Reliabilitas dihitung dengan melakukan uji internal consistency menggunakan Cronbach's 
alpha pada skor total dan keempat subskala R-MSPSS. Validitas konstruk dianalisis menggunakan Confirmatory factor analysis (CFA) dengan estimasi diagonally weighted least square.

\section{Hasil Penelitian dan Pembahasan}

Data demografi dari 285 responden dijabarkan pada tabel 1 di bawah ini. Responden penelitian ini didominasi oleh perempuan $(75,09 \%)$. Guru-guru yang mengajar di kota Bandung sebagian besar tinggal di wilayah Kota Bandung $(73,68 \%)$. Selain di kota Bandung, ada juga guru yang tinggal di wilayah kabupaten Bandung (16,46\%), kabupaten Bandung Barat $(3,86 \%)$, dan Kota Cimahi (5,96\%). Responden didominasi latar belakang budaya dari suku Sunda $(81,40 \%)$.

Tabel 1. Demografi Responden

\begin{tabular}{lll}
\hline Karakteristik Responden & $\boldsymbol{n}$ & \% \\
\hline Jenis Kelamin & & \\
Laki-laki & 71 & 24,91 \\
Perempuan & 214 & 75,09 \\
Jenjang sekolah yang diajar & & \\
SD & 85 & 29,83 \\
SMP & 109 & 38,25 \\
SMA/SMK & 91 & 31,93 \\
Pengalaman & mengajar & \\
(tahun) & & \\
>5 & 57 & 20,00 \\
5-15 & 89 & 31,23 \\
16-25 & 76 & 26,67 \\
>25 & 63 & 22,11 \\
Tempat tinggal & & \\
Kota Bandung & 210 & 73,68 \\
Kab. Bandung & 47 & 16,49 \\
Kab. Bandung Barat & 11 & 3,86 \\
Kota Cimahi & 17 & 5,96 \\
Suku budaya & & \\
Sunda & 232 & 81,40 \\
Jawa & 36 & 12,63 \\
Lainnya & 17 & 5,96 \\
\hline
\end{tabular}

R-MSPSS memiliki nilai cronbach's alpha total sebesar 0,89. Tabel 2 menunjukkan bahwa setiap subskala R-MSPSS memiliki nilai cronbach's alpha dalam rentang 0,72 hingga 0,83. Hasil tersebut menunjukkan bahwa R-MSPSS memiliki reliabilitas yang baik dengan nilai cronbach's alpha >0,7 (Hair, Black, Babin, \& Anderson, 2019).

Tabel 2. Karakteristik Item dan Reliabilitas

\begin{tabular}{|c|c|c|c|c|}
\hline & $\begin{array}{l}\text { Cronbach's } \\
\text { alpha }\end{array}$ & $\begin{array}{l}\text { Item-total } \\
\text { correlation }\end{array}$ & mean & sd \\
\hline Kepala Sekolah & $\mathbf{0 , 8 3}$ & & & \\
\hline $\begin{array}{l}\text { 1. Kepala sekolah saya bersedia untuk fleksibel } \\
\text { dalam bekerja sehingga kehidupan kerja saya } \\
\text { menjadi lebih ringan. }\end{array}$ & & 0,56 & 5,54 & 1,43 \\
\hline 3. Saya bisa mengandalkan kepala sekolah ketika & & 0,65 & 4,86 & 1,55 \\
\hline
\end{tabular}


saya mengalami kesulitan dalam bekerja.

7. Kepala sekolah saya mudah untuk diajak bicara.

13. Kepala sekolah saya bersedia mendengarkan masalah-masalah pribadi saya.

\section{Rekan Guru}

2. Guru-guru lain bersedia untuk fleksibel dalam bekerja sehingga kehidupan kerja saya menjadi lebih ringan.

4. Saya bisa mengandalkan guru-guru lain ketika saya mengalami kesulitan dalam bekerja.

8. Guru-guru lain mudah untuk diajak bicara.

14. Guru-guru lain bersedia mendengarkan masalah-masalah pribadi saya.

\section{Keluarga}

5. Keluarga saya benar-benar berupaya untuk membantu saya.

6. Saya mendapatkan dukungan emosional yang saya butuhkan dari keluarga.

11. Saya dapat menceritakan masalah-masalah saya kepada keluarga.

15. Keluarga saya mau membantu saya dalam membuat keputusan.

\section{Teman}

9. Teman teman saya (Non-kolega) berusaha untuk membantu saya.

10. Saya dapat mengandalkan teman-teman saya (non kolega) ketika saya menghadapi masalah.

12. Saya mempunyai teman (non-kolega) sebagai tempat berbagi suka dan duka.

16. Saya dapat menceritakan masalah saya dengan teman-teman saya (non kolega).

$\begin{array}{lll}0,59 & 5,19 & 1,37 \\ 0,44 & 6,19 & 1,01\end{array}$

$\mathbf{0 , 7 2}$

\begin{tabular}{|c|c|}
\hline 0,46 & 5,85 \\
\hline 0,48 & 5,78 \\
\hline 0,63 & 4,99 \\
\hline 0,63 & 5,33 \\
\hline
\end{tabular}

$\mathbf{0 , 8 3}$

\begin{tabular}{|c|c|}
\hline 0,59 & 6,07 \\
\hline 0,53 & 6,26 \\
\hline 0,54 & 6,08 \\
\hline 0,51 & 6,14 \\
\hline
\end{tabular}

$\mathbf{0 , 8 2}$

\begin{tabular}{|c|c|}
\hline 0,59 & 5,52 \\
\hline 0,61 & 5,23 \\
\hline 0,33 & 6,03 \\
\hline 0,43 & 4,98 \\
\hline
\end{tabular}

Pada gambar 1 dibawah ini menunjukkan hasil uji CFA pada 4 faktor R-MSPSS dengan metode estimasi diagonally weighted least square. Korelasi antar variabel berada pada rentang 0,43 hingga 0,78. Didapatkan juga factor loading yang berada pada rentang 0,48 hingga 0,93. Jumlah sampel 285 memperbolehkan factor loading > 0,35 untuk dipertahankan (Hair et al., 2019). Hasil uji goodness of fit menunjukkan bahwa R-MSPSS dengan 4 faktor memiliki kriteria goodfit dengan nilai CFI >0,95; TLI > 0,95; RMSEA < 0,08; SRMR < 0,08 dan GFI > 0,95 (Hooper, Coughlan, \& Mullen, 2008; Hu \& Bentler, 1999) 


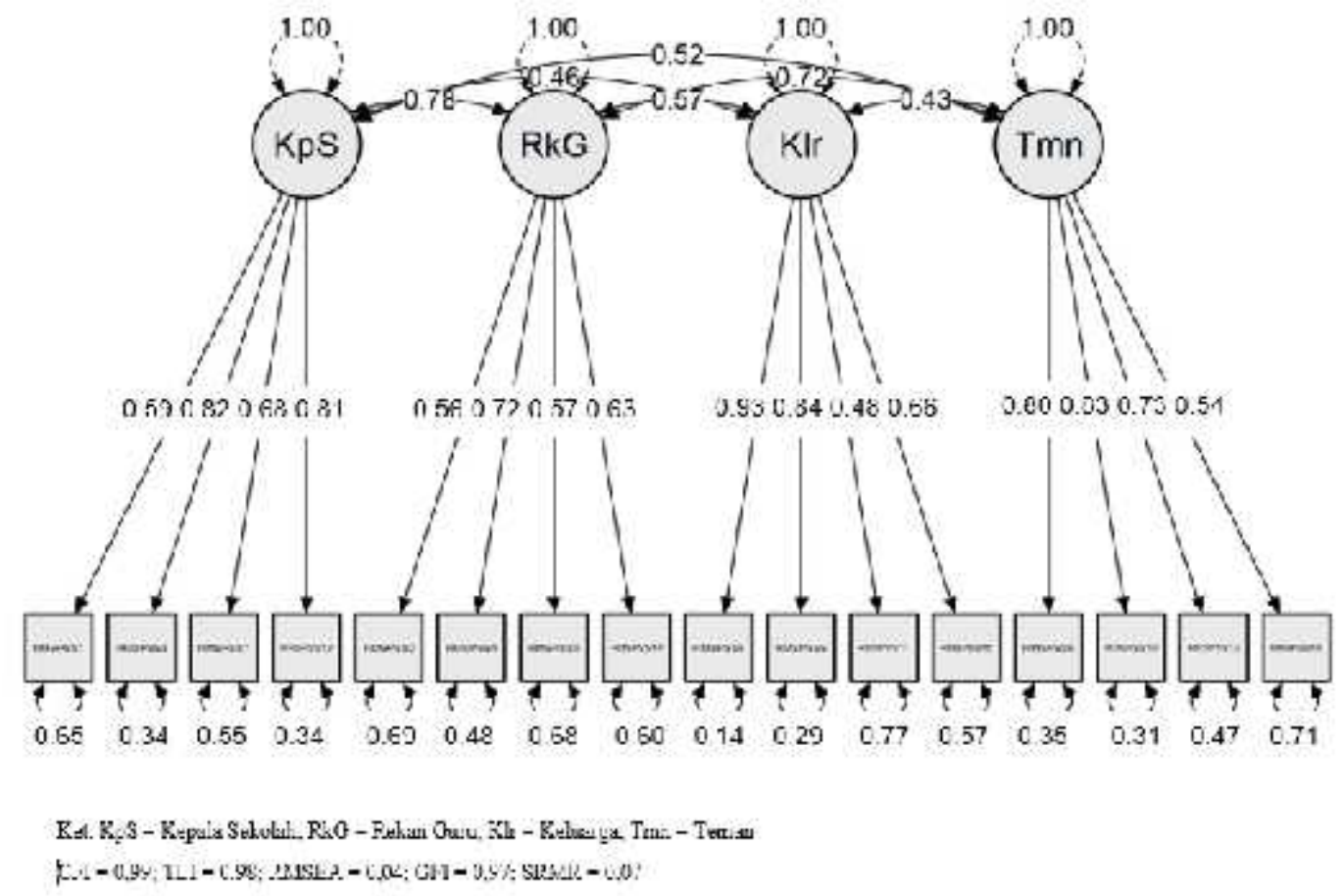

Gambar 1. Analisis faktor konfirmatori

Hasil penelitian ini menunjukkan bahwa instrumen R-MSPSS memiliki reliabilitas yang baik dengan koefisien cronbach's alpha 0,72 hingga 0,82 serta goodness of fit yang didapatkan dari CFA. Hal ini menunjukkan bahwa R-MSPSS merupakan instrumen yang reliabel dan valid untuk mengukur persepsi dukungan sosial guru SD, SMP, dan SMA/SMK di Kota Bandung. Reliabilitas pada subskala keluarga dan subskala teman memiliki kemiripan dengan MSPSS yang diujikan pada remaja di Indonesia (Laksmita et al., 2020).

Berbeda dengan penelitian R-MSPSS sebelumnya (Ho \& Chan, 2017) pada penelitian ini tidak perlu dilakukan perubahan pada model berdasarkan modification indices. Penggunaan metode estimasi diagonally weighted least square meminimalisir kesalahan perhitungan yang dapat terjadi pada data tidak berdistribusi normal. Pada sampel guru di China, kemiripan item antara subskala kepala sekolah dengan subskala rekan guru dianggap sebagai penyebab diberlakukannya perubahan pada model berdasarkan modification indices (Ho \& Chan, 2017). Pada sampel guru SD, SMP, dan SMA/SMK di kota Bandung, kemiripan item pada subskala kepala sekolah dengan subskala rekan guru tidak menyebabkan dibutuhkannya perubahan model berdasarkan modification indices.

RMSPSS berbeda dengan MSPSS pada subskala significant other yang digantikan dengan subskala kepala sekolah dan subskala rekan guru (Ho \& Chan, 2017). Hal ini dibenarkan oleh penelitian awal MSPSS (Zimet et al., 1988) karena significant other dapat diartikan sebagai orang yang berbeda pada populasi yang berbeda. Kata asli dari penelitian di China adalah principal dan coworker sehingga kalimatnya juga dapat digunakan dalam konteks pekerjaan selain guru. Pada penelitian ini principal dispesifikkan menjadi kepala sekolah dan coworker diterjemahkan menjadi rekan guru agar lebih sesuai dengan konteks guru di sekolah.

\section{Kesimpulan}

Kesimpulan yang diperoleh dari hasil penelitian ini adalah Revised Multidimensional Scale of Perceived Social Support (R-MSPSS) merupakan instrumen yang valid dan reliabel untuk 
mengukur persepsi guru terhadap dukungan sosial pada guru SD, SMP, dan SMA/SMK di kota Bandung. Instrumen ini telah dapat digunakan untuk dasar penentuan intervensi mengenai dukungan sosial guru.

\section{Saran}

R-MSPSS dapat digunakan untuk menggambarkan perceived social support pada guru. Gambaran mengenai perceived social support tersebut dapat dijadikan dasar oleh guru, sekolah, praktisi, dan pemerintah untuk melaksanakan intervensi untuk mengembangkan dukungan sosial. Penelitian selanjutnya disarankan melakukan uji reliabilitas dan validitas dengan sampel pada kota-kota lain di Indonesia untuk kesesuaian instrumen R-MSPSS pada sampel-sampel tersebut dan memeroleh norma yang lebih luas.

\section{Daftar Pustaka}

Akbar, Z., \& Tahoma, O. (2018). Dukungan Sosial dan Resiliensi Diri pada Guru Sekolah Dasar. Jurnal Penelitian Dan Pengukuran Psikologi, 7(1), 53-59. https://doi.org/10.21009/JPPP.071.07

Clipa, O. (2017). Teacher Stress and Coping Strategies. In O. Clipa (Ed.), Studies and Current Trends in Science of Education (pp. 120-128). https://doi.org/10.18662/lumproc.icsed2017.14

Cohen, S. (2004). Social Relationships and Health. American Psychologist, 59(8), 676-684. https://doi.org/10.1037/0003-066X.59.8.676

Denis, A., Callahan, S., \& Bouvard, M. (2015). Evaluation of the French Version of the Multidimensional Scale of Perceived Social Support During the Postpartum Period. Maternal and Child Health Journal, 19(6), 1245-1251. https://doi.org/10.1007/s10995-014-1630-9

Giena, V. P., Thongpat, S., \& Nitirat, P. (2018). Predictors of health-promoting behaviour among older adults with hypertension in Indonesia. International Journal of Nursing Sciences, 5(2), 201-205. https://doi.org/10.1016/j.ijnss.2018.04.002

Guan, N. C., Seng, L. H., Hway Ann, A. Y., \& Hui, K. O. (2015). Factorial Validity and Reliability of the Malaysian Simplified Chinese Version of Multidimensional Scale of Perceived Social Support (MSPSS-SCV) Among a Group of University Students. Asia Pacific Journal of Public Health, 27(2), 225-231. https://doi.org/10.1177/1010539513477684

Hair, J. F., Black, W. C., Babin, B. J., \& Anderson, R. E. (2019). Multivariate Data Analysis. In Mathematics of Computation (Eight Edit). Retrieved from https://www.jstor.org/stable/2007941? origin=crossref

Ho, S. K., \& Chan, E. S. (2017). Modification and validation of the multidimensional scale of perceived social support for Chinese school teachers. Cogent Education, 4(1), 1-11. https://doi.org/10.1080/2331186X.2016.1277824

Hooper, D., Coughlan, J., \& Mullen, M. (2008). Structural Equation Modelling: Guidelines for Determining Model Fit. Electronic Journal of Business Research Methods, 6(1), 53-60. https://doi.org/10.21427/D7CF7R

Hu, L., \& Bentler, P. M. (1999). Cutoff criteria for fit indexes in covariance structure analysis: Conventional criteria versus new alternatives. Structural Equation Modeling: $\quad A \quad$ Multidisciplinary Journal, $\quad 6(1), \quad 1-55$. https://doi.org/10.1080/10705519909540118

JASP Team. (2020). JASP (Version 0.14)[Computer software]. Retrieved from https://jaspstats.org/ 
Lakey, B., \& Cohen, S. (2000). Social Support Theory and Measurement. In Social Support Measurement and Intervention (pp. 29-52). https://doi.org/10.1093/med:psych/9780195126709.003.0002

Laksmita, O. D., Chung, M. H., Liao, Y. M., \& Chang, P. C. (2020). Multidimensional Scale of Perceived Social Support in Indonesian adolescent disaster survivors: A psychometric evaluation. PLoS ONE, 15(3), 1-12. https://doi.org/10.1371/journal.pone.0229958

LAM, B. (2019). Understanding Social Support. In Social Support, Well-being, and Teacher Development (pp. 29-83). https://doi.org/10.1007/978-981-13-3577-8_2

Lee, S. C., Moy, F. M., \& Hairi, N. N. (2017). Validity and Reliability of the Malay version Multidimensional Scale of Perceived Social Support (MSPSS-M) among Teachers. Quality of Life Research, 26(1), 221-227. https://doi.org/10.1007/s11136-016-1348-9

Park, H., Nguyen, T., \& Park, H. (2012). Validation of multidimensional scale of perceived social support in middle-aged Korean women with diabetes. Asia Pacific Journal of Social Work and Development, 22(3), 202-213. https://doi.org/10.1080/02185385.2012.691719

Theofilou, P. (2015). Translation and cultural adaptation of the Multidimensional Scale of Perceived Social Support for Greece. Health Psychology Research, 3(1), 45-47. https://doi.org/10.4081/hpr.2015.1061

Thoits, P. A. (2011). Mechanisms Linking Social Ties and Support to Physical and Mental Health. Journal of Health and Social Behavior, 52(2), 145-161.

Zimet, G. D., Dahlem, N. W., Zimet, S. G., \& Farley, G. K. (1988). The Multidimensional Scale of Perceived Social Support. Journal of Personality Assessment, 52(1), 30-41. https://doi.org/10.1207/s15327752jpa5201_2 